\title{
Power system transient stability analysis in networks with renewable generation considering variable correlations
}

\section{Document Version}

Accepted author manuscript

Link to publication record in Manchester Research Explorer

\section{Citation for published version (APA):}

Qi, B., \& Milanovic, J. V. (2018). Power system transient stability analysis in networks with renewable generation considering variable correlations. In 11th IET International Conference on Advances in Power System Control, Operation and Management (APSCOM 2018)

\section{Published in:}

11th IET International Conference on Advances in Power System Control, Operation and Management (APSCOM 2018)

\section{Citing this paper}

Please note that where the full-text provided on Manchester Research Explorer is the Author Accepted Manuscript or Proof version this may differ from the final Published version. If citing, it is advised that you check and use the publisher's definitive version.

\section{General rights}

Copyright and moral rights for the publications made accessible in the Research Explorer are retained by the authors and/or other copyright owners and it is a condition of accessing publications that users recognise and abide by the legal requirements associated with these rights.

\section{Takedown policy}

If you believe that this document breaches copyright please refer to the University of Manchester's Takedown Procedures [http://man.ac.uk/04Y6Bo] or contact uml.scholarlycommunications@manchester.ac.uk providing relevant details, so we can investigate your claim.

\section{OPEN ACCESS}




\title{
Power System Transient Stability Analysis in Networks with Renewable Generation Considering Variable Correlations
}

\author{
Buyang QI, Jovica V. MILANOVIĆ \\ The University of Manchester \\ Manchester, UK \\ buyang.qi@manchester.ac.uk, jovica.milanovic@manchester.ac.uk, tel: +44(0)1613068724
}

\begin{abstract}
Modern Power Systems are equipped with new technologies like renewable energy sources (RES) and flexible power-consuming devices. These new technologies introduce uncertainties in system generating and loading profiles which in turn affect the dynamic characteristics, and the stable operation of the system might be at risk. This paper employs sensitivity analysis method for the identification and ranking of critical uncertain parameters affecting transient stability in a large meshed network with renewable generation. Copula method is used in this paper in order to model the correlations between uncertain parameters based on real system data. The paper develops methodology for identifying influential parameters which have the dominant effect on network transient stability behaviour. "Heat Map" is used as graphical representation of the results on which the influence of system uncertainties is clearly demonstrated. Economic and optimal operation of the power system in terms of stability can be achieved through concentrating resources in the monitoring and fine-tuning of the identified critical parameters.
\end{abstract}

Keywords-Copula method, renewable generation, sensitivity analysis, transient stability

\section{INTRODUCTION}

Modern power systems are characterised by the increasing penetration of Distributed Energy Resources (DERs). These DERs can be in the form of power electronics interfaced Renewable Energy Sources (RES) which exhibit intermittent characteristic in system generation. The uncertainties introduced by RES, together with market/load driven uncertainties, result in an overall increase of system uncertain parameters. The dynamic signature of modern power systems can be significantly changed with more and more new technologies like DERs, replacing conventional generators for better operational efficiency, reduced $\mathrm{CO}_{2}$ emissions and enhance flexibility. It is very important to investigate the effect of uncertain parameters on power system stability from the perspective of secure operation of modern power systems.

Traditional deterministic stability analysis is no longer suitable when uncertainties are introduced in power systems since the 'worst case scenario' analysis may lead to an overly conservative system design [1-3]. Probabilistic transient stability assessment (TSA) has hence been used widely by researchers, and it is proved to be an appropriate way to assess the influence of system uncertainties on transient stability [4-6]. The Monte Carlo simulations are commonly used to perform this kind of probabilistic studies [5, 6]. In conventional power systems the uncertainties that are normally considered are those associated with the system loading and fault location/duration [5-8]. More and more studies, e.g. [9], are investigating the impact of penetration of DERs on power system dynamics. This paper combines the two in a way and considers the uncertainties in DERs (Wind generation and PhotoVoltaics generation) and system loading, and assesses their influence on system transient stability.

Considering that typical modern power systems are large and that the number of uncertain parameters is increasing, the conventional Monte Carlo simulations for power system stability analysis can be time and resources consuming. In such cases, priority ranking of system uncertain parameters based on their influence on system dynamics can help the operators to allocate resources to accurate estimation of critical parameters and use only those to perform fast online assessment. Previous studies employed sensitivity analysis (SA) techniques for the identification of influential parameters affecting voltage/small-disturbance stability within a network with RES generation [10-12]. The advanced Morris screening sensitivity analysis method (MSSA) is compared with the commonly used local sensitivity analysis method (LSA) and the global sensitivity analysis method (GSA) and its efficiency and accuracy have been demonstrated. This paper expands the application of MSSA to transient stability analysis.

Most of the above studies use independent probability distributions for modelling parameter uncertainty. Due to the fact that the input datasets for uncertain parameters are randomly generated, they fail to capture the correlations among uncertainties within the real system, hence the results of the analysis may not be accurate [13-15]. The Copula theory has been employed in the past for this purpose, i.e., for the modelling of correlations among system parameters. A throughout comparison between different copula families when different dependence structures are required is presented in [15]. The multivariate Gaussian copula is reported as the most effective and accurate approach for representation of the correlations between uncertainties involved in this study.

This paper employs MSSA for the priority ranking of critical parameters affecting power system transient stability. The multivariate Gaussian copula is introduced for correlation 
modelling between uncertain parameters. The main focus of this paper is to identify the group of critical parameters which have dominant effect on system transient stability. The importance of considering correlations between uncertain parameters is also demonstrated. The approach developed can be used for fast on-line system security and risk-assessment and set references for system operators.

\section{METHODOLOGY}

The priority ranking of system uncertain parameters based on their influence on network transient stability follows 4 major steps: (i) initially, proper probability distribution functions are applied to generate dataset of uncertain parameters, and copula approach is employed for correlation modelling of input parameters; (ii) the Optimal Power Flow (OPF) is solved in order to determine the conventional generation dispatching; (iii) the Transient Stability Indices are calculated; (iv) the SA approach is applied for the identification of critical parameters affecting power system transient stability.

\section{A. Stability Indices}

There are two indices used in this paper for the quantification of the impact of uncertain parameters on system transient stability.

The first index is the transient stability index (TSI) as defined in [16]. The TSI is capable of the assessment of nonoscillatory behaviour of generators in TSA, given by Equation (1).

$$
T S I=100 * \frac{360-\delta_{\max }}{360+\delta_{\min }}
$$

In Equation (1), $\delta_{\max }$ is the maximum rotor angle separation between any two generators in system after a fault. A negative TSI value indicates that a generator or a group of generators is out of synchronism with the rest of the system and the system is unstable. For positive TSI values, the larger the TSI the more stable the system is.

The second index is the settling time of the rotor angle of each generator. This index is used as the indication of oscillatory stability, given by Equation (2)

$$
\text { Oscillatory Stability }=\left|\frac{\delta_{i} \text { final }-\delta_{i} \text { initial }}{\delta_{i} \text { initial }}\right| * 100 \%
$$

Equation (2) measures the magnitude of oscillations of each generator's rotor angle after a period of time after the fault. The system is considered to settle to a new steady state if the index value is smaller than 5\% [9].

\section{B. Probabilistic Modelling of Uncertain Input Parameters}

This paper follows the probabilistic approach of TSA; hence the probabilistic modelling of the system uncertain parameters is employed. The uncertain parameters considered in this paper are system loads, wind speed for wind farm and solar irradiation for PV generating. Table I illustrates the
Table I

Probabilistic Distribution and Model Parameters of System Uncertainties of the Test Network

\begin{tabular}{cccc}
\hline \hline $\begin{array}{c}\text { Uncertain } \\
\text { Parameter }\end{array}$ & $\begin{array}{c}\text { Probability } \\
\text { Distribution }\end{array}$ & $\begin{array}{c}\text { Probabilistic } \\
\text { Model } \\
\text { Parameters }\end{array}$ & $\begin{array}{c}\text { Level of } \\
\text { Uncertainty }\end{array}$ \\
\hline $\begin{array}{c}\text { Load Demand } \\
(\%)\end{array}$ & Normal & $3 \delta=10 \%$ of $\mu$ & \\
\hline $\begin{array}{c}\text { Wind Speed } \\
\left(m s^{-1}\right)\end{array}$ & Weibull & $\alpha=2.2, \beta=11.1$ & $10 \%$ \\
\hline $\begin{array}{c}\text { Solar } \\
\text { Irradiation }\end{array}$ & Beta & $\mathrm{a}=13.7, \mathrm{~b}=1.3$ & \\
$\left(\mathrm{kWh} h^{-2}\right)$ & & & \\
\hline \hline
\end{tabular}

probability distribution for selected system uncertainties and their corresponding model parameters.

\section{Priority Ranking of System Uncertain Parameters}

The identification of critical system parameters is performed by using sensitivity analysis (SA). The SA approaches describe numerically how the input uncertainties can affect the output variabilities after they go through a modelled system. This paper employs the advanced MSSA for the priority ranking of critical parameters affecting system transient stability. The MSSA is designed to perform a designated semi-global search among the input variabilities. It is recommended by [10-12] as an efficient approach for the priority ranking of uncertain parameters in large meshed network from the perspective of stability analysis.

Equations (3), (4), and (5) are the sensitivity indices defined for the MSSA method, named as elementary effects, mean of elementary effects and standard deviation of the elementary effects, respectively [17].

$$
\begin{aligned}
& E E_{p}^{i}(x)= \frac{\left[y\left(x_{1}, x_{2}, \ldots, x_{i-1}, x_{i}+\Delta, x_{i+1}, \ldots, x_{p}\right)-y(x)\right]}{\Delta} \\
& \mu_{p}^{*}=\frac{1}{r} \sum_{i=1}^{r}\left|E E_{p}^{i}\right| \\
& \sigma_{p}^{*}=\sqrt{\frac{1}{r} \sum_{i=1}^{r}\left(\left|E E_{p}^{i}\right|-\mu_{p}^{*}\right)^{2}}
\end{aligned}
$$

In Equation (4), $\mu_{\mathrm{p}}^{*}$ serves as the ranking score for individual input uncertainties. The value of the score demonstrates the influence of the corresponding uncertainty. The higher the $\mu_{\mathrm{p}}^{*}$ is, the more influential is the uncertainty considered. A higher score in $\sigma_{\mathrm{p}}^{*}$ indicates the corresponding input uncertainty has a non-linear effect on the output. $p$ is the number of input uncertainties, $r$ is the 'level' of MSSA (usually between 4 to 10 , higher $\mathrm{r}$ values can provide more accurate simulation results), and $\Delta$ is the step size determined through $\Delta=\frac{1}{\mathrm{r}-1}$. The number of simulations required for MSSA isn $=p * r+1$. The semi-global search within input parameters makes the computational burden of MSSA significantly lower compared to conventional GSA method such as, for example, the Sobol total indices method $[10,11]$ 


\section{ACCEPTED VERSION OF THE PAPER}

\section{Correlations between Input Uncertainties}

The copula method is capable of generating a correlated input dataset for modelled uncertainties in power systems. [15] suggested that the multivariate Gaussian (mvG) copula is an accurate and efficient approach for the modelling of system uncertain parameters from the perspective of power system stability analysis. The mvG copula provides the flexibility to model a higher number of dimensions, and is very useful to model relationships among the variables when the individual variables are from different distributions. This has been adopted here as the modelled uncertainties namely, system load, wind and solar data follow different probability distributions as shown in Table 1.

Equation (6) defines the copula function for the $\mathrm{mvG}$ copula.

$C\left(u_{1}, u_{2}, \ldots, u_{n} ; \Sigma\right)=\phi_{\Sigma}\left[\phi^{-1}\left(u_{1}\right), \phi^{-1}\left(u_{2}\right), \ldots, \phi^{-1}\left(u_{n}\right)\right](6)$

In Equation (6), $\Sigma$ denotes a symmetric, positive definite matrix withdiag $(\Sigma)=\mathrm{I}, \quad \phi_{\Sigma}$ is the multivariate normal distribution with correlation matrix $\Sigma$, and $\phi^{-1}(\boldsymbol{\square})$ is the inverse of the Normal cumulative distribution function (cdf).

The correlation matrix $\Sigma$ (or the covariance matrix) in Equation (6) is expressed as Equation (7)

$$
\Sigma=\left[\begin{array}{ccc}
1 & \cdots & \rho_{1 n} \\
\vdots & \ddots & \vdots \\
\rho_{n 1} & \cdots & 1
\end{array}\right]
$$

The covariance matrix in this paper is formed with the Pearson correlation coefficient $\rho$ obtained from real data of the IEEE NETS-NPYS (New England Test System-New York Power System) test system.

\section{E. Monte-Carlo Stopping Rule}

The correlation modelling of uncertain parameters employs the Monte Carlo simulation. A certain number of repeated random sampling of the uncertain data is required when Monte Carlo simulation is used to represent the stochastic behaviour. Equation (8) determines the required Monte Carlo run [18].

$$
\varepsilon>\left[\frac{\left\{\phi^{-1}\left(1-\frac{\delta}{2}\right) * \sqrt{\frac{\sigma^{2}(X)}{N}}\right\}}{\bar{X}}\right]
$$

In Equation (8), $\varepsilon$ is the sample mean error, $\phi^{-1}(\cdot)$ is the inverse Gaussian conditional probability distribution with a zero mean value and a one standard deviation value, $\sigma^{2}(\cdot)$ is the variance of a sample, $\delta$ is the required confidence level, and $\overline{\mathrm{X}}$ is the mean of the samples.

Previous studies on the IEEE 68-Bus NETS-NYPS test system indicated that for transient stability studies the sampling number required for a $5 \%$ sample mean error with 99\% confidence interval is 6000 simulations [9]. However it is also demonstrated in [9] that 1000 simulations are enough as more simulations tend to give the same results but at a higher cost of time.

\section{TEST NETWORK}

This study employs the 16 machines, 68 buses reduced order modified equivalent model of the New England Test System and the New York Power System (NETS-NYPS)[19], see Fig. 1. The test network consists of 5 sections, with generator G1-G9 in the NETS area, generator G10-G13 in the NYPS area, and G14, G15, G16 in 3 equivalent areas connected to NYPS. The renewable generation is integrated by using 7 equivalent wind generators and 7 equivalent PV generators. The renewable generators are connected to 7 system buses (buses 60, 57, 68, 26, 53, 33, and 17) to simulate the distributed energy resources. The wind turbines are modelled as Doubly Fed Induction Generators (DFIGs) and the PV-plants are modelled as Full Converter Connected Generators (FCCs). The total number of the considered uncertain parameters is 66 (including 52 load buses and 14 RES generators). Hence the total number of simulation runs for MSSA is 661 with $r=10$ levels. However due to the fact that there exist 17 buses which do not have a load connected (no load uncertainty), the number of ranked system uncertainties is 49 .

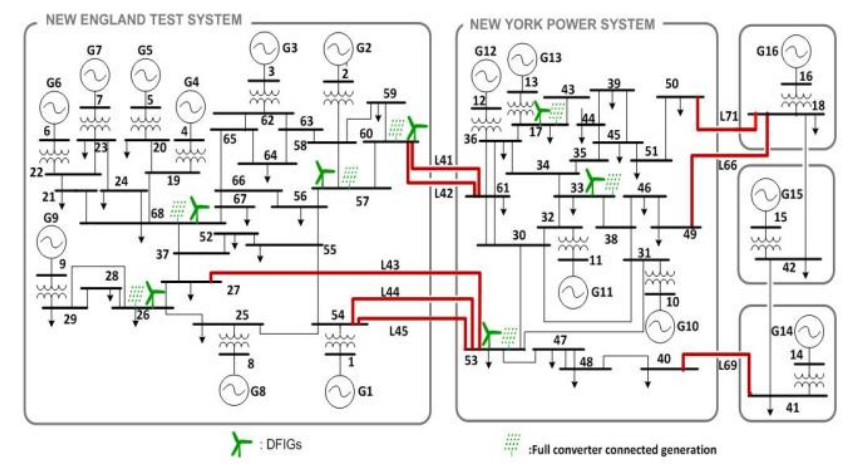

Figure 1: Modified IEEE 68-Bus NETS-NYPS test system with RES generations.

The loads in this study are all modelled to be the classical exponential load model. Equations (9) and (10) define the load model used in the test network.

$$
\begin{gathered}
P_{L}=P_{n}\left(\frac{U}{U_{n}}\right)^{0} \\
Q_{L}=Q_{n}\left(\frac{U}{U_{n}}\right)^{2}
\end{gathered}
$$

In Equations (9) and (10), $\mathrm{P}_{\mathrm{L}}$ and $\mathrm{Q}_{\mathrm{L}}$ are the active and reactive power, respectively, drawn by the loads at voltage magnitude $U . P_{n}$ and $Q_{n}$ are the active and reactive load drawn by the loads when the system is operating at rated voltage $U_{n}$.

Study also considers different loading levels for the assessment of system dynamic behaviour under various loading conditions. The analysed loading levels are selected from the daily loading curve with the values of $0.3 \mathrm{p} . \mathrm{u}, 0.6 \mathrm{p} . \mathrm{u}$ and 1.0p.u. In Equation (11) and (12), the renewable 
generation penetration level $\mathrm{PL}_{\mathrm{RES}}$ is calculated. $\mathrm{P}_{\mathrm{L}}$ is the system loading, $\mathrm{G}_{\mathrm{SM}}$ is the active power generation from synchronous machines and $G_{\text {RES }}$ is the active power generation from RES generations. The system loading levels and their corresponding PL $_{\text {RES }}$ are listed in Table II.

$$
\begin{aligned}
& P_{L}=G_{S M}+G_{R E S} \\
& P L_{R E S}=\frac{G_{R E S}}{P_{L}}
\end{aligned}
$$

Table II

The RES Generation Penetration Level under Variable Loading Demand Selected from Daily Loading Curve

\begin{tabular}{cccc}
\hline \hline Loading Demand & 1.0 p.u & $0.6 \mathrm{p} . u$ & $0.3 \mathrm{p} . \mathrm{u}$ \\
\hline$P L_{R E S}$ & $20 \%$ & $33 \%$ & $67 \%$ \\
\hline \hline
\end{tabular}

The simulations run in this study are performed using two software platforms. The probabilistic modelling of input parameters (with/without Correlation Modelling), the data analysis for MSSA and the calculation of the optimal power flow (OPF) are carried out in Matlab. The RMS simulation for TSA is performed in DIgSILENT PowerFactory.

\section{IV.ILLUSTRATIVE RESULTS AND DISCUSSION}

\section{A. Priority Ranking for Transient Stability}

The priority ranking of critical parameters affecting power system transient stability is performed through sensitivity analysis. The disturbance employed is a three-phase fault on a transmission line followed by the line disconnection. The fault duration is set to be 13 cycles in this study [20]. The rotor angles of all synchronous generators are recorded for 20 seconds to illustrate system transient dynamic behaviour.

There are six transmission lines selected for fault deployment and line disconnection. This is to demonstrate the influence of fault location on power system transient stability behaviour. The selected six transmission lines are line 12 (between buses 21 and 68, near critical generator G9), line 56 (between buses 33 and 38, near critical generator G11), line 42 (between buses 60 and 61, tie-line between NETS-NYPS), line 45 (between buses 53 and 54, tie-line between NETSNYPS), line 70 (between buses 40 and 41, tie-line between
NYPS-G14) and line 72 (between buses 18 and 50, tie-line between NYPS-G16).

Figure 2 employs heatmap for the demonstration of the priority ranking of the parameters affecting power system transient stability. The heatmap is divided into three major sections. It demonstrates the system transient stability behaviour under the selected 1p.u, 0.6p.u and 0.3p.u loading conditions, respectively. It is observed that for fault applied to line 12 and 56 (near critical, low inertia generators G9 and G11), the uncertainties in large system loads (L17 with 6000MW, L18 with $2470 \mathrm{MW}$, L41 with $1150 \mathrm{MW}$ etc.) are identified to be more influential compared to other uncertainties considered in this study. However it can also be observed that when the fault is applied to line 42, 45, 70 and 72 , i.e., further away from critical generators, the transient stability of the test network is not anymore that much dominated by the large loads. Figure 2 also demonstrates that as the proportion of RES penetration level increases, the importance of the RES increases, and hence the uncertainties of wind and PV generators are becoming influential when the system loading levels decrease to 0.6 p.u and 0.3 p.u.

\section{B. Ranking considering the correlations between Uncertainties}

The correlations between the input system uncertainties are considered to both, represent the real operating conditions more accurately and investigate the importance of accurate correlation modelling. The system uncertainties and their correlation patterns are obtained from[21, 22]. Figure 3 is a $49 * 49$ matrix (trained from the actual test network data) of Pearson correlation coefficients among 49 system uncertain parameters. In this figure, rows/columns 1-35 are system loads, 36-42 are wind speed and 43-49 are solar irradiance.

The intra-dependence and inter-dependence within the parameter groups can be easily identified in Figure 3. For example, five groups of closely located system loads are highlighted through their high intra-dependence structure. These identified load-load intra-dependence structures can be explained as the results of different lifestyles of their corresponding consumers (industry/living load, weather depended load, etc.). For the intra-dependence structures between wind-wind and PV-PV, they are mainly influenced

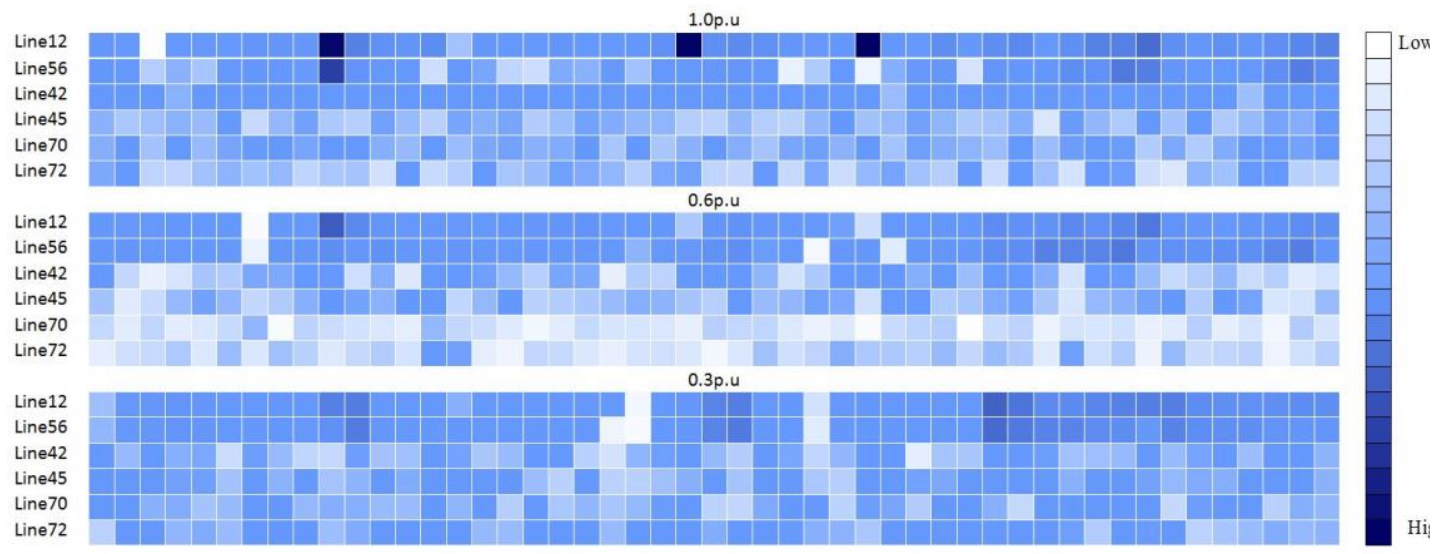

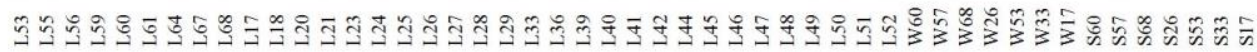

Figure 2: Heatmap of ranking for transient stability index showing different system loading. 
by the distance between the RES generators, as the weather pattern can be similar for closely located generation plants. It should be noticed that for PV-PV correlation, the intradependence structures are very strong as they are determined by day-time hours when the sampling time scale is very long, in this case over a year.

The inter-dependence structures between load-wind and wind-load are low. This indicates the parameters in load and wind generation are poorly correlated. The inter-dependence structures between load-PV and PV-load are relatively high. This is true as people need to turn on lights during working hours and night-time, or use AC during summer time with longer daylight time.

Figure 4 shows a heatmap which indicates the identified influential parameters for power system transient stability analysis when the correlations between input parameters are considered. The groups of system loads from L41 to L49 and L17 to L26 are identified as influential parameters affecting test network transient stability performance. The influence of the uncertainties in loads is generally bigger than the uncertainties in RES generation as the loading condition is at 1p.u and the RES penetration level is low.

The importance of accurate modelling of the correlations between input parameters is illustrated by comparing Figure 2 and 4. When independent probabilistic modelling of the system parameters is applied, the loss of correlation between parameters can lead to the omission of an important parameter which may not be influential on its own but is highly correlated to an influential parameter. This is not desirable for risk-based assessment as the risk of a critical condition may be ignored and result in system failure.

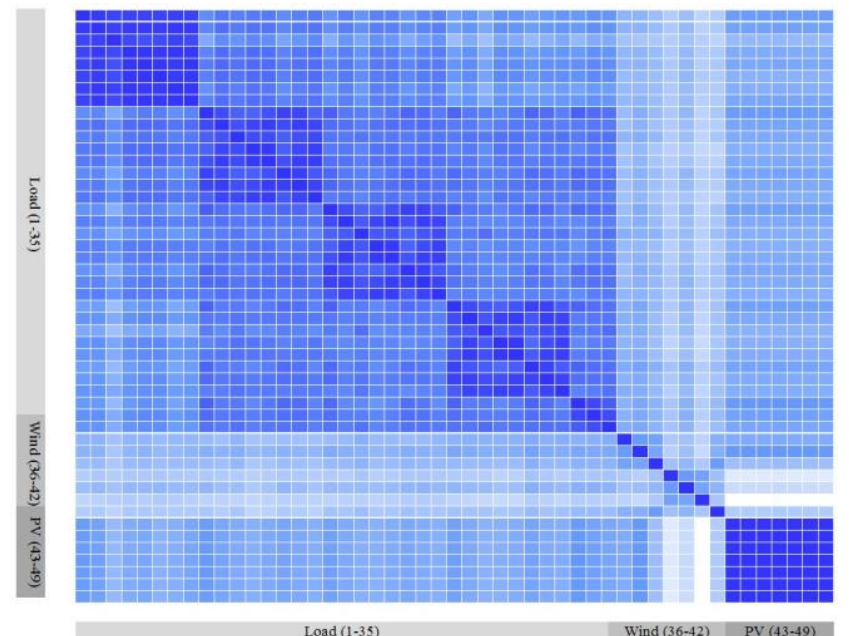

Figure 3: Stochastic dependence structure of NETS-NPYS load, wind speed and solar irradiance over a year.
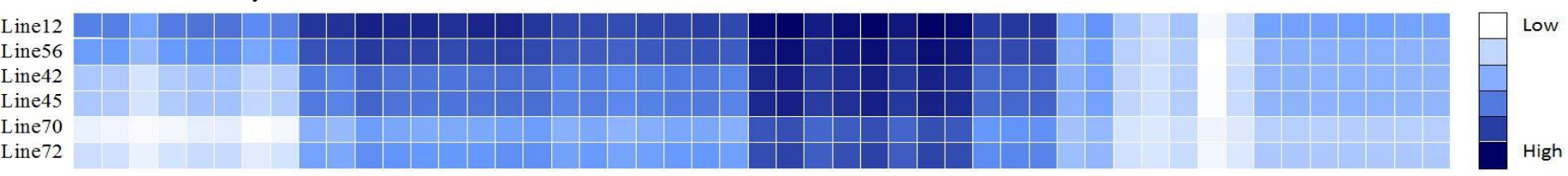

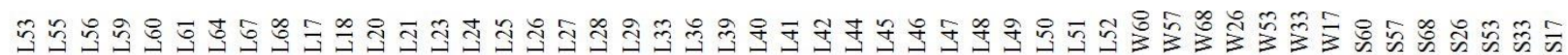

Figure 4: Ranking of critical parameters for transient stability when correlations between input parameters are considered.
Table III

Effect of Fault Duration and RES Penetration Level on Transient Stability Performance

\begin{tabular}{|c|c|c|c|c|c|}
\hline \multirow{3}{*}{$\begin{array}{l}\text { Fault } \\
\text { Line }\end{array}$} & \multirow{3}{*}{$\begin{array}{c}\text { RES } \\
\text { Penetration } \\
\text { Level }\end{array}$} & \multicolumn{4}{|c|}{ Fault Duration } \\
\hline & & \multicolumn{2}{|c|}{10 cycles } & \multicolumn{2}{|c|}{13 cycles } \\
\hline & & TSI & $\begin{array}{c}\text { No. of } \\
\text { Oscillatory } \\
\text { Instability }\end{array}$ & TSI & $\begin{array}{c}\text { No. of } \\
\text { Oscillatory } \\
\text { Instability }\end{array}$ \\
\hline \multirow{3}{*}{ Line 42} & $20 \%$ & 63 & 9 & 61 & 569 \\
\hline & $33 \%$ & 72 & 661 & 70 & 661 \\
\hline & $67 \%$ & 76 & 661 & 76 & 657 \\
\hline \multirow{3}{*}{ Line 56} & $20 \%$ & 61 & 251 & 57 & 509 \\
\hline & $33 \%$ & 70 & 661 & 68 & 661 \\
\hline & $67 \%$ & 77 & 661 & 76 & 661 \\
\hline \multirow{3}{*}{ Line 70} & $20 \%$ & 67 & 190 & 72 & 569 \\
\hline & $33 \%$ & 75 & 544 & 75 & 635 \\
\hline & $67 \%$ & 80 & 341 & 80 & 385 \\
\hline
\end{tabular}

Finally, the study considered the effect of fault duration RES penetration level on the test network transient this different pre-fault conditions. In addition the settling time of the rotor angle of each generator is employed as an indication of oscillatory stability. The advanced MSSA with 661 simulations is used again to obtain the above mentioned two stability indices. The average value of the TSI among all 661 mulation runs is calculated, and the number of cases where shown in Table III.

In Table III, case studies with fault applied on line 42 , line and line 70 are illustrated for demonstration purpose. Two fault durations, 10 cycles and 13 cycles are considered and it no effects on TSI values, which means that the considered test network transient stability is mostly determined by its prefault conditions (Note that longer than usual fault durations of 10 and 13 cycles are adopted to generate sufficient number of unstable cases with considered test network. Otherwise one typically consider faults lasting 4-7 cycles at level on test network transient stability analysis is also demonstrated in Table III. In this study, the optimal power calculation will de-load and/or disconnect synchronous generation is kept constant hence the RES penetration level will increase. The lower system loading level results in a higher TSI value though the number of unstable cases first 
increases and then starts to decrease again. The actual effect of RES on transient stability is determined by the number of de-loaded (the rotational reserve increases while the inertia of the system remains the same) and disconnected (the rotational reserve and inertia in the system decrease) synchronous generators at the time of fault and the ride through characteristics and control settings of RES, hence careful consideration of all these parameters is required prior to any generalisation.

\section{CONCLUSIONS}

This paper employs sensitivity analysis for the priority ranking of critical parameters affecting power system transient stability in a system with RES generation. The multivariate Gaussian copula is applied to the input data set for the correlation modelling of input parameters. The results of the priority rankings of critical parameters with/without parameter correlation are then compared to demonstrate the importance of the accurate modelling of the correlation structures between input data set while performing power system transient stability related analysis. This paper reveals the disadvantage of independent modelling of system parameters during real network dynamic analysis. This is due to the fact that even though some of the system parameters may be uninfluential on their own, their variation/uncertainty can have a significant impact on system dynamic behaviour due to their correlation with other influential parameters. The large system loads (namely L17, L18, L42, etc.) and those loads highly correlated are considered to have critical effect on test network transient stability behaviour. It can also be observed that the influence of the uncertainties in RES generation increases when the RES penetration level increases as the system inertia decreases due to conventional generator disconnection.

The fast and accurate priority ranking of critical parameters is favoured in power system stability related analysis as it can help to narrow down the number of parameters which are critical for stable operation of the power system. Resources can then be concentrated on the selected parameters to achieve better management of the system with less monitoring. The approach proposed in this paper can also be used to establish the system security profile under various conditions. Fast and accurate tuning of the system can then be achieved by mapping the operation conditions into the system security profile.

\section{References}

[1] C. W. Group, "Review of the current status of tools and techniques for risk-based and probabilistic planning in power systems," WG 601 of SC C4, 2010.

[2] W. Li and J. Zhou, "Probabilistic reliability assessment of power system operations," Electric Power Components and Systems, vol. 36, pp. 1102-1114, 2008.

[3] J. McCalley, S. Asgarpoor, L. Bertling, R. Billinion, H. Chao, J. Chen, et al., "Probabilistic security assessment for power system operations," in Power Engineering Society General Meeting, 2004. IEEE, 2004, pp. 212-220.

[4] P. N. Papadopoulos and J. V. Milanović, "Probabilistic framework for transient stability assessment of power systems with high penetration of renewable generation," IEEE Transactions on Power Systems, vol. 32, pp. 3078-3088, 2017.

[5] E. Vaahedi, W. Li, T. Chia, and H. Dommel, "Large scale probabilistic transient stability assessment using BC Hydro's online tool," IEEE Transactions on Power Systems, vol. 15, pp. 661$667,2000$.

[6] P. M. Anderson and A. Bose, "A probabilistic approach to power system stability analysis," IEEE Transactions on Power Apparatus and Systems, pp. 2430-2439, 1983.

R. Billinton and P. Kuruganty, "Probabilistic assessment of transient stability in a practical multimachine system," IEEE Transactions on Power Apparatus and Systems, pp. 3634-3641, 1981.

[8] H. Yuan-Yih and C. Chung-Liang, "Probabilistic transient stability studies using the conditional probability approach," IEEE transactions on power systems, vol. 3, pp. 1565-1572, 1988.

[9] P. N. Papadopoulos and J. V. Milanović, "Impact of penetration of non-synchronous generators on power system dynamics," in PowerTech, 2015 IEEE Eindhoven, 2015, pp. 1-6.

[10] K. N. Hasan, R. Preece, and J. V. Milanović, "Priority ranking of critical uncertainties affecting small-disturbance stability using sensitivity analysis techniques," IEEE Transactions on Power Systems, vol. 32, pp. 2629-2639, 2017.

[11] B. Qi and J. V. Milanovic, "Identification of critical parameters affecting voltage stability in networks with renewable generations using sensitivity analysis methods," in PowerTech, 2017 IEEE Manchester, 2017, pp. 1-6.

[12] Y. Zhu and J. V. Milanović, "Efficient identification of critical load model parameters affecting power system voltage stability," in PowerTech, 2017 IEEE Manchester, 2017, pp. 1-6.

[13] N. Zhang, C. Kang, C. Singh, and Q. Xia, "Copula based dependent discrete convolution for power system uncertainty analysis," IEEE Transactions on Power Systems, vol. 31, pp. 5204-5205, 2016.

[14] W. Wu, K. Wang, B. Han, G. Li, X. Jiang, and M. L. Crow, "A versatile probability model of photovoltaic generation using pair copula construction," IEEE Transactions on Sustainable Energy, vol. 6, pp. 1337-1345, 2015.

[15] K. N. Hasan and R. Preece, "Influence of stochastic dependence on small-disturbance stability and ranking uncertainties," IEEE Transactions on Power Systems, vol. 33, pp. 3227-3235, 2018.

[16] D. Gautam, V. Vittal, and T. Harbour, "Impact of increased penetration of DFIG-based wind turbine generators on transient and small signal stability of power systems," IEEE Transactions on power systems, vol. 24, pp. 1426-1434, 2009.

[17] A. Saltelli, K. Chan, and E. M. Scott, Sensitivity analysis vol. 1: Wiley New York, 2000.

[18] R. Preece and J. V. Milanović, "Efficient estimation of the probability of small-disturbance instability of large uncertain power systems," IEEE Transactions on Power Systems, vol. 31, pp. 1063-1072, 2016.

[19] G. Rogers, Power system oscillations: Springer Science \& Business Media, 2012.

[20] T. Guo and J. V. Milanović, "Online identification of power system dynamic signature using PMU measurements and data mining," IEEE Transactions on Power Systems, vol. 31, pp. 17601768, 2016.

A. ERCOT, TX, USA. (2017). Hourly Load Data Archives. Available: http://www.ercot.com/gridinfo/load/load hist/ AgriMet. (2017). Historical Dayfile Data Access. Available: https://www.usbr.gov/pn/agrimet/webaghrread.html 